\title{
Primary sciatic nerve lymphoma: a case report and review of the literature
}

\author{
M J L Descamps, L Barrett, M Groves, L Yung, R Birch, N M F Murray, D C Linch, M P T Lunn, \\ M M Reilly
}

J Neurol Neurosurg Psychiatry 2006;77:1087-1089. doi: 10.1136/jnnp.2006.087577

A patient with primary B cell non-Hodgkin's lymphoma of the sciatic nerve is described. He presented with neuropathic symptoms in the left leg, initially diagnosed as tarsal tunnel syndrome. Magnetic resonance imaging (MRI) identified the abnormality in the sciatic nerve. A fascicular biopsy of the sciatic nerve showed a diffuse large B cell non-Hodgkin's lymphoma. The patient was treated with chemotherapy and rituximab (anti-CD20 monoclonal antibody). Four months later he was in remission, and remains so 48 months from presentation. Primary lymphoma of single peripheral nerves may be a unique subtype of extranodal lymphoma, which usually follows an aggressive course and has a variable response to current therapeutic strategies. MRI is useful, alongside electrophysiological studies, in patients with atypical peripheral nerve symptoms.

$P$ rimary central nervous system lymphomas account for $1 \%$ of all primary lymphomas, whereas primary peripheral nervous system lymphomas are distinctly unusual. Rarer still is an isolated mononeuropathy as a manifestation of neurolymphomatosis: only eight cases of primary sciatic nerve lymphoma have been reported. We describe a patient with solitary infiltration of the left sciatic nerve by a diffuse large B cell lymphoma and discuss this case with reference to the literature.

\section{CASE REPORT}

A 55-year-old man presented to his local hospital in November 2001 with weakness and pain in his left foot. Eighteen months previously, he noted his inability to curl the toes of his left foot. This was associated with numbness of the sole of the same foot. A diagnosis of tarsal tunnel syndrome was made. His symptoms remained unchanged until July 2002, when he developed intermittent tightening in his left calf. Four months later, he presented to the National Hospital for Neurology and Neurosurgery, London, UK. He was unable to stand on the toes of his left foot, and the numbness had spread to the whole left sole and the back of the leg. He had developed severe pain in the back of his left thigh, radiating down to the ankle, very similar to the sciatica he had experienced 10 years previously on the right side. He was well systemically. On examination, the neurological abnormalities were confined to his left leg. No wasting was evident, but there was severe weakness in the muscle groups innervated by the tibial nerve and numbness in the Sl dermatome. All deep tendon reflexes were intact and the plantar responses flexor. General examination was unremarkable other than a pigmented lesion on his back.

Blood tests, including full blood count and erythrocyte sedimentation rate, were normal.
Nerve conduction studies showed an absent left posterior tibial motor response from abductor hallucis, with a normal left common peroneal motor amplitude from extensor digitorum brevis ( $4.2 \mathrm{mV}$ at ankle). The left sural sensory action potential was $16 \mu \mathrm{V}$ initially, but fell to $6 \mu \mathrm{V}$ in a month. Electromyography showed denervation changes in the gastrocnemius and abductor hallucis, but not tibialis anterior, consistent with a tibial or sciatic nerve lesion.

Magnetic resonance imaging (MRI) of the lumbosacral spine was normal, but MRI of the thighs showed diffuse swelling and oedema of the sciatic nerve from below the buttock to the level of the popliteal fossa on the left. The extent of swelling was thought to be unusual for a neurogenic tumour (fig $1 \mathrm{~A}, \mathrm{~B}$ ).

Cerebrospinal fluid (CSF) was normal except for oligoclonal bands, matched in CSF and serum.

The pigmented skin lesion on the patient's back was removed and found to be a malignant melanoma of low metastatic potential (Clark level 2, Breslow thickness $0.5 \mathrm{~mm}$ ). Positron emission tomography showed high uptake in the sciatic nerve area, but also in the upper lobe of each lung. High-resolution computed tomography of the thorax showed ill-defined ground glass shadowing, but no mass lesion. Non-malignant lymphocytes were found by bronchoalveolar lavage. Together, the pulmonary findings were compatible with sarcoidosis.

A fascicular biopsy of the sciatic nerve lesion was carried out. Haematoxylin and eosin-stained sections of the biopsy showed that the single fascicle was surrounded by an abnormal perineurium-like sheath. The endoneurium was heavily infiltrated, with large, pleomorphic and mitotically active lymphoid cells. The abnormal cells were immunoreactive for CD20 (fig lC) and Bcl-2, with nearly $100 \%$ proliferation fraction by Ki-67 immunostaining (fig 1E), indicating a B lymphocyte immunophenotype. None were immunoreactive for S100, HMB45, cytokeratin and epithelial membrane antigen. Immunostaining for CD45RO showed a small reactive $\mathrm{T}$ lymphocyte population. The pan-axonal marker PGP9.5 showed numerous unmyelinated axons traversing the tumour (fig 1D). The epineurium surrounding the fascicle also contained large numbers of CD20immunoreactive lymphoma cells, particularly concentrated in and around blood vessel walls.

Plastic sections of $1 \mu \mathrm{m}$ showed myelin debris and degenerating myelinated fibres interspersed with these cells, with occasional small myelinated fibres (fig IF) and numerous capillaries.

Electron microscopy of the endoneurium showed scattered Remak bundles and denervated Schwann cell processes (not shown). The endoneurium was bound by elongated cells, separated by bands of collagen. These cells did not show the features of perineurial cells, did not form a continuous sheath, and may represent a type of dedifferentiated perineurial cell. 

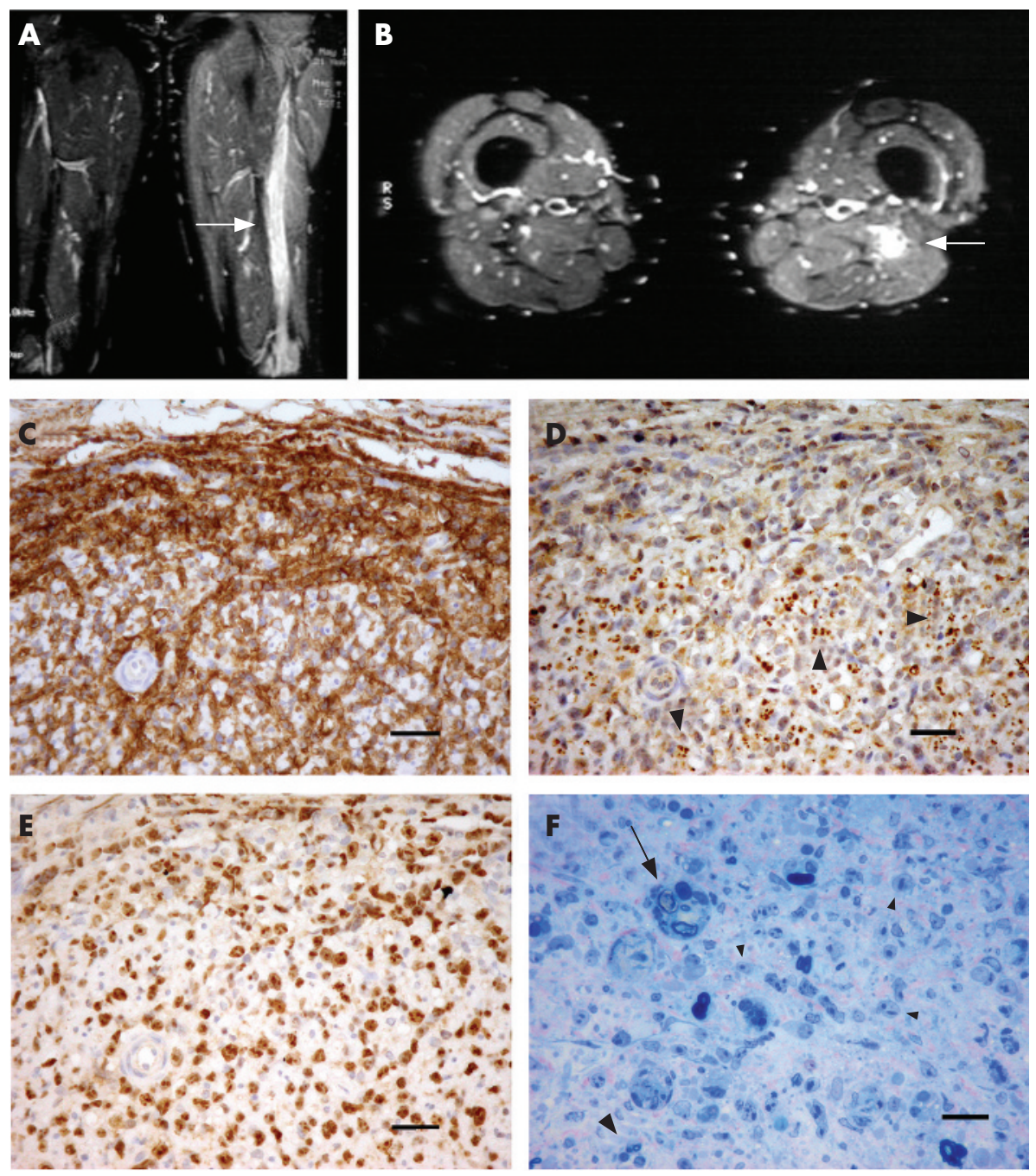

Figure 1 T2-weighted magnetic resonance imaging of the thighs $(A, B)$. High signal is present in the left sciatic nerve as compared with the right in coronal (A) and axial sections (B) (arrows), consistent with an infiltrating mass. High signal extends throughout the length of the sciatic nerve and is associated with swelling and oedema in the surrounding muscle. Fascicular biopsy of the sciatic nerve (C-F), immunostained with anti-CD20 (C), PGP9.5 (D) and Ki-67 (E). The endoneurium is heavily infiltrated with large pleomorphic cells immunoreactive for CD20 and some surrounding blood vessels (C). Remaining small, largely unmyelinated fibres, in Remak bundles (arrow heads), persist throughout the tumour (D). Ki-67 staining shows a proliferation index of nearly $100 \%$ (E). $1-\mu \mathrm{m}$ resin sections show a few degenerating myelinated fibres (arrow) and a few persisting small myelinated fibres (large arrowhead) interspersed with the numerous abnormal tumour cells (small arrowheads) (F). Scale bars $40 \mu \mathrm{m}(\mathrm{C}-\mathrm{E})$ and $20 \mu \mathrm{m}$ (F).
A diffuse large B cell non-Hodgkin's lymphoma of the left sciatic nerve was diagnosed. Staging by bone marrow biopsy and computed tomography of the abdomen and pelvis showed no spread of disease.

The patient was treated with six cycles of systemic chemotherapy with cyclophosphamide, doxorubicin, vincristine and prednisolone and four infusions of anti-CD20 monoclonal antibody rituximab. By March 2003, the patient was in clinical remission. His pain completely resolved within days of treatment, but there was no change in the weakness or sensory loss. He remains in clinical remission 48 months from presentation.

\section{DISCUSSION}

The literature has eight previous case reports of primary lymphoma of the sciatic nerve (table 1 ). In addition, there are five reports of primary lymphoma without systemic involvement at other peripheral nerve sites, including the brachial plexus, the ulnar, median and radial nerves, and the sympathetic chain. ${ }^{1-4}$

Table 1 compares the clinical and histological features of the nine reported primary sciatic nerve lymphomas. All patients presented with a history of progressive pain, weakness and sensory disturbance in the distribution of the sciatic nerve. Three cases were initially misdiagnosed as either lumbar disc pathology ${ }^{5}$ or tarsal tunnel syndrome (current report). In each case, there was no clinical or radiological evidence of lymphoma outside the peripheral nervous system at the time of diagnosis. The methods used to detect extraneural disease have varied among the published reports, with use of MRI and whole body isotope scans in the more recent cases. In all nine cases a bone marrow biopsy was negative. CSF examination was only documented in two previous $\operatorname{cases}^{78}$ and was normal. Our case had matched oligoclonal bands.

It is of interest that our patient had two other seemingly unrelated pathologies (malignant melanoma and possible sarcoidosis), which complicated the diagnostic process.

More than $95 \%$ of extranodal lymphoid malignancies are non-Hodgkin's lymphoma ${ }^{9}$ and all the sciatic nerve cases reported are of this type. Of them, eight cases were found to be of $\mathrm{B}$ cell lineage, with only one instance of $\mathrm{T}$ cell lymphoma. ${ }^{6}$ Although different authors have used different histological classifications, a trend towards intermediate or high-grade malignancy was seen in all cases. The prevalence of B cell lymphomas of relatively high grade corresponds with that reported for primary lymphoid malignancies of the CNS.

It is unclear why there is a predilection for the sciatic nerve. Quinones-Hinojosa et $\mathrm{al}^{8}$ postulated that B cells may reside or originate in the sciatic nerve. More likely, specific cell adhesion molecule expression is the basis for tissue targeting, ${ }^{10}$ but these are yet to be identified. The absence of disease elsewhere suggests that primary lymphoma of the peripheral nerve may have unique characteristics. Increasingly, advanced methods are able to exclude extraneural disease. A review of the published cases, however, shows that primary 
Table 1 Clinical and histological features of the nine cases of reported sciatic nerve lymphoma

\begin{tabular}{|c|c|c|c|c|c|c|c|}
\hline Case & Age & Sex & Side & $\begin{array}{l}\text { Histology } \\
\text { (criteria set) }\end{array}$ & Grade & Treatment & Outcome \\
\hline Purohit et al & 64 & $\mathrm{~F}$ & Right & $\begin{array}{l}\text { B cell NHL } \\
\text { centrocytic (Kiel) }\end{array}$ & Low & Resection, radiotherapy & $\begin{array}{l}\text { Evidence of systemic disease } \\
36 \text { months after clinical onset }\end{array}$ \\
\hline Pillay et $a^{5}$ & 61 & M & Left & $\begin{array}{l}\text { B cell NHL diffuse } \\
\text { large cell (IWF) }\end{array}$ & Intermed & Radiotherapy & $\begin{array}{l}\text { No evidence of disease } \\
12 \text { months after clinical onset }\end{array}$ \\
\hline Eusebi et $a l^{11}$ & 72 & M & Right & $\begin{array}{l}\text { B cell NHL follicular } \\
\text { large cell (IWF) }\end{array}$ & Intermed & Resection, chemotherapy & $\begin{array}{l}\text { Died of systemic disease } \\
16 \text { months after clinical onset }\end{array}$ \\
\hline Kanamori et $a l^{\beta}$ & 34 & M & Left & $\begin{array}{l}\mathrm{T} \text { cell NHL } \\
\text { lymphoblastic }\end{array}$ & High & Chemotherapy, radiotherapy & $\begin{array}{l}\text { No evidence of disease } \\
30 \text { months after clinical onset }\end{array}$ \\
\hline Roncaroli et al & 44 & M & Left & $\begin{array}{l}\text { B cell NHL diffuse } \\
\text { large cell (IWF) }\end{array}$ & Intermed & Radiotherapy, chemotherapy & $\begin{array}{l}\text { Died of CNS disease } 50 \text { months } \\
\text { after clinical onset }\end{array}$ \\
\hline $\begin{array}{l}\text { Quinones- } \\
\text { Hinojosa et } a l^{\beta}\end{array}$ & 52 & M & Right & $\begin{array}{l}\text { B cell NHL Burkitt- } \\
\text { like (REAL) }\end{array}$ & High & Chemotherapy & $\begin{array}{l}\text { Died of CNS/PNS disease } \\
\text { approx. } 18 \text { months after clinical } \\
\text { onset }\end{array}$ \\
\hline \multirow[t]{2}{*}{ Misdraji et al ${ }^{4}$} & 62 & $\mathrm{~F}$ & Left & $\begin{array}{l}\text { B cell NHL diffuse } \\
\text { large cell (REAL) }\end{array}$ & High & Radiotherapy, chemotherapy & $\begin{array}{l}\text { Stable local residual disease } \\
57 \text { months after clinical onset }\end{array}$ \\
\hline & 49 & M & Right & $\begin{array}{l}\text { B cell NHL diffuse } \\
\text { large cell (REAL) }\end{array}$ & High & Chemotherapy & Died of CNS disease at 6 months \\
\hline Present case & 55 & M & Left & $\begin{array}{l}\text { B cell NHL diffuse } \\
\text { large cell (REAL) }\end{array}$ & High & $\begin{array}{l}\text { Chemotherapy and anti- } \\
\text { CD20 }\end{array}$ & $\begin{array}{l}\text { No evidence of disease } \\
48 \text { months after clinical onset }\end{array}$ \\
\hline
\end{tabular}

CNS, central nervous system; Intermed, intermediate; IWF, International Working Formulation; F, female; M, male; NHL, non-Hodgkin's lymphoma; PNS, peripheral nervous system; REAL, revised European-American classification of lymphoid neoplasms.

lymphoma at this site may herald the development of more widespread and aggressive disease. Only three of the cases had a postmortem examination. ${ }^{4}{ }^{11}$ Interestingly, none showed malignant lymphoma in the reticuloendothelial system, but all found more extensive neurological involvement than could be detected by imaging in other peripheral nerves, spinal nerve roots and the arachnoid space. This finding, in combination with the limited diffusion of chemotherapeutic agents across a blood-nerve barrier, ${ }^{8}$ may explain the poor outcomes and the propensity to recur in the CNS.

The optimal treatment for primary peripheral nerve lymphomas is still debated. The outcome appears to be poor despite nerve resection, local radiotherapy or systemic chemotherapy (table 1). Of four cases (including the current report) in which the patients survived without evidence of systemic disease, ${ }^{4-6}$ three have follow-up periods $<3$ years. This is too short a period to fully assess tumour behaviour. One patient was alive with stable residual disease at 57 months. ${ }^{4}$ It has been suggested that myeloablative chemotherapy, prophylactic treatment of the CNS and even limb amputation may be required. ${ }^{7}$ Our patient received rituximab in addition to chemotherapy with cyclophosphamide, doxorubicin, vincristine and prednisolone, because it is thought to sensitise the malignant cells to the effects of chemotherapy; there is evidence that in elderly patients, outcome is improved when rituximab is given with systemic chemotherapy. ${ }^{12}$ Trials in younger patients are ongoing.

Nine reported cases of primary non-Hodgkin's lymphoma of the sciatic nerve are now available. The presentation of the disease is indolent and diagnosis may be difficult initially. The natural history of the disease seems to be aggressive and the optimal treatment is unclear. MRI is extremely useful in helping to diagnose peripheral nerve lymphomas and should be considered alongside electrophysiological studies in all cases of atypical sciatica.

\section{Authors' affiliations}

M J L Descamps, L Barrett, N M F Murray, M P T Lunn, M M Reilly, Centre for Neuromuscular Diseases, National Hospital for Neurology and Neurosurgery, Queen Square, London, UK
R Birch, Peripheral Nerve Injury Unit, Royal National Orthopaedic Hospital NHS Trust, Brockley Hill, Stanmore, Middlesex, UK

M Groves, Department of Molecular Neurosciences, Institute of

Neurology, Queen Square

L Yung, D C Linch, Haematology Department, University College, London

\section{Competing interests: None.}

Informed consent was obtained for publication of the patient's details described in this report.

Correspondence to: M M Reilly, National Hospital for Neurology and Neurosurgery, Queen Square, London WCIN 3BG, UK; m.reilly@ion.ucl.ac.uk

Received 3 January 2006

Revised version received 3 January 2006

Accepted 5 March 2006

\section{REFERENCES}

1 Usuki K Yuo A, Muto $Y$, et al. Primary malignant lymphoma of the left brachial plexus. Rinsho Ketsueki 1988;29:1125-8.

2 Teissier J. Primary malignant lymphoma localized in the trunk of the ulnar nerve at the elbow. A case report. Ann Chir Main Memb Super 1992;11:170-2.

$3 \mathrm{Kim}$ J, Kim YS, Lee EJ, et al. Primary CD56-positive NK/T-cell lymphoma of median nerve: a case report. J Korean Med Sci 1998;13:331-3.

4 Misdraji J, Ino Y, Louis DN, et al. Primary lymphoma of peripheral nerve: report of four cases. Am J Surg Pathol 2000;24:1257-65.

5 Pillay PK, Hardy RW Jr, Wilbourn AJ, et al. Solitary primary lymphoma of the sciatic nerve: case report. Neurosurgery 1988;23:370-1.

6 Kanamori M, Matsui H, Yudoh K. Solitary T-cell lymphoma of the sciatic nerve: case report. Neurosurgery 1995;36:1203-5.

7 Roncaroli F, Poppi M, Riccioni L, et al. Primary non-Hodgkin's lymphoma of the sciatic nerve followed by localization in the central nervous system: case report and review of the literature. Neurosurgery 1997:40:618-21.

8 Quinones-Hinojosa A, Friedlander RM, Boyer PJ, et al. Solitary sciatic nerve lymphoma as an initial manifestation of diffuse neurolymphomatosis. Case report and review of the literature. J Neurosurg 2000;92:165-9.

9 Purohit DP, Dick DJ, Perry RH, et al. Solitary extranodal lymphoma of sciatic nerve. J Neurol Sci 1986;74:23-34.

10 Baehring JM, Damek D, Martin EC, et al. Neurolymphomatoisis. Neuro Oncology 2003:5:104-15.

11 Eusebi V, Bondi A, Cancellieri A, et al. Primary malignant lymphoma of sciatic nerve. Report of a case. Am J Surg Pathol 1990;14:881-5.

12 Coiffier B, Lepage E, Briere J, et al. CHOP chemotherapy plus rituximab compared with CHOP alone in elderly patients with diffuse large-B-cell lymphoma. N Engl J Med 2002;346:235-42. 